Check for updates

Cite this: RSC Adv., 2021, 11, 34820

\title{
Novel potentiometric sensors for determination of ondansetron hydrochloride in pure and dosage form
}

\author{
Amina M. Abass, (D) ${ }^{a}$ Sahar S. M. Alabdullah, (D) *ab Omar Salih Hassan ${ }^{\text {}}$ \\ and Ahmed Ahmed (iD a
}

A new and sensitive potentiometric method has been developed and characterized for four novel sensors responsive to ondansetron hydrochloride. The potentiometric sensor method includes advancement of ondansetron hydrochloride sensors using a membrane comprised of molybdophosphoric acid (MPA) and ondansetron as an electro-active material in a polyvinylchloride (PVC) matrix membrane plasticized with di-butyl phthalate (DBPH), ortho-nitrophenyloctyl ether (O-NPOE), di-octyl phthalate (DOPH), or dibutyl phosphate (DBP). The validity of sensors in the present work has been examined, and steady and reproducible responses were obtained over the concentration ranges of $7.3 \times 10^{-5}$ to $1.0 \times 10^{-2}, 6.6 \times$ $10^{-6}$ to $1.0 \times 10^{-2}, 1.0 \times 10^{-5}$ to $1.0 \times 10^{-2}$, and $2.0 \times 10^{-5}$ to $1.0 \times 10^{-2} \mathrm{M}$ for DBPH-, O-NPOE-, $\mathrm{DOPH}-$, and DBP-ondansetron, respectively. The sensors revealed Nernstian gradients of $59.61 \pm 0.50$, $57.71 \pm 0.23,53.01 \pm 0.14$, and $53.20 \pm 0.35 \mathrm{mV}$ per decade individually with $\mathrm{pH}$ ranges of $2.5-5.5 \mathrm{in}$ DBPH and 3.5-5.0 in O-NPOE electrodes, and 4.0-5.5 for both individual DOPH and DBP plasticized film-based sensors. The time responses for the sensors were 30, 32, 31, and 29 s for DBPH-, O-NPOE-, $\mathrm{DOPH}-$, and DBP-ondansetron, respectively. The developed sensors also exhibited high selectivity towards ondansetron hydrochloride against different interfering species of inorganic particles with longterm stability of approximately $41,36,18$, and multiple days for the DBPH, O-NPOE, DOPH, and DBP electrodes.

Received 27th April 2021

Accepted 7th October 2021

DOI: $10.1039 / \mathrm{d} 1 \mathrm{ra03268b}$

rsc.li/rsc-advances

\section{Introduction}

The structure of ondansetron hydrochloride (ODH) is $(R S)-9$ methyl-3-[(2-methyl-1H-imidazole-1-yl)methyl]-1,2,3,9-tetrahydro-4H-carbazol-4-one hydrochloride dihydrate ${ }^{1}$ (Fig. 1), and it is a basic compound with a $K_{\mathrm{a}}$ of 7.7. It is a specific serotonin 5HT3 receptor antagonist that is used to treat nausea and vomiting caused by cancer chemotherapy and radiotherapy. It has also been shown to have neuroleptic and anti-anxiety characteristics. ${ }^{2,3}$ For anti-anxiety, the normal dosage is $8-32 \mathrm{mg}$ per day, and for anxiety disorder, the initial results from clinical recommendations suggested lower levels of 2-4 $\mathrm{mg}$ per day. ${ }^{3}$

Over time, methods have been developed for the determination of ondansetron by liquid chromatography (LC), ${ }^{\mathbf{4 , 5}}$ highperformance liquid chromatography (HPLC), ${ }^{6,7}$ ion-pair chromatography, ${ }^{8}$ liquid chromatography mass spectrometry (LCMS), ${ }^{\mathbf{9}, 10}$ capillary zone electrophoresis, ${ }^{11,12}$ flow injection atomic absorption spectroscopy, and ultraviolet

(UV)

${ }^{a}$ Department of Chemistry, College of Science, Al-Nahrain University, Baghdad, Al-Jaderia, Iraq.E-mail: sasahar1982@gmail.com

${ }^{b}$ Materials Centre, School of Chemistry, University of Leicester, Leicester LE1 7RH, UK ${ }^{c}$ Departments of Chemistry, College of Education for Pure Science, Tikrit University, Tikrit, Iraq spectrophotometry. ${ }^{13-15}$ Ninama et al. improved and validated a mass spectrometry method for concentrations of 1.00-100.00 $\mathrm{ng} \mathrm{mL} \mathrm{m}^{-1}$ with a lower limit of quantitation (LLOQ) at approximately $1.00 \mathrm{ng} \mathrm{mL} \mathrm{m}^{-1}$, and shorter stability time for analysis of ondansetron solutions at approximately $7 \mathrm{~h} 10 \mathrm{~min}$. This process is long and time consuming for routine regulatory analysis of the quality of pharmaceutical dosage forms. ${ }^{\mathbf{1 6}}$ However, Farnoush et al. introduced a reliable and rapid potentiometric sensor for ondansetron with an acceptable Nernstian slope of $58 \pm 0.3 \mathrm{mV}$, and the author also employed the sensor in ionic liquid solvents, such as 1-butyl-3methylimidazolium tetrafluoroborate $\left([\mathrm{BMIM}]\left[\mathrm{BF}_{4}\right]\right) .{ }^{17} \quad \mathrm{~A}$ further important issue with the use of $[\mathrm{BMIM}]\left[\mathrm{BF}_{4}\right]$ is that the<smiles>Cc1nccn1CC1CCc2c(c3ccccc3n2C)C1=O</smiles>

Fig. 1 Structure of ondansetron hydrochloride. 
liquid junction potential $\left(E_{\mathrm{j}}\right)$ could possibly accrue when different solutions are used due to different mobility of ions. ${ }^{18}$

The drawbacks of the above studies have been the included number of complex processes, limited applications, and required derivatization responses for measuring ondansetron. Another challenge is that there are few existing analytical methods with sensors of sufficient sensitivity that can be used to measure ondansetron in bioequivalence studies. ${ }^{19}$ A new approach is therefore required to overcome the weaknesses of published methods and devise accurate and sensitive techniques.

Thus, the overall goal of the current study was to improve a new version of potentiometric polymer matrix membrane sensors so that they were sufficiently accurate to measure trace amounts of ondansetron. The sensors successfully measured ondansetron in a bioequivalence pharmaceutical form, which was achieved using polyvinylchloride (PVC) as a matrix membrane plasticized with electro-active materials acting as ion pair complexes with either dibutyl phthalate, $o$-nitrophenyl octylether, di-octyl phthalate, or di-butyl phosphate in molybdophosphoric acid ondansetron.

\section{Experimental}

\subsection{Chemical preparations}

All analytical reagents were prepared in deionised water. Molybdophosphoric acid (MPA) and tetrahydrofuran (THF) were purchased from Aldrich and used without further purification. Polyvinylchloride (PVC) Breon S110/10 was purchased from B.P. Chemical UK, Ltd, whilst $o$-nitrophenyl octyl ether, dibutyl phthalate, di-octyl phthalate, and di-butyl phosphate were purchased from Fluka and BDH. Pure ondansetron hydrochloride was supplied by the State Company of Drug Industries and Medical Appliances (IRAQ-SDI, Samara). The formulated ondansetron hydrochloride tablets used were Zofran, $4 \mathrm{mg}$, manufactured in Singapore, and Zofran, $8 \mathrm{mg}$, manufactured in Egypt.

\subsection{Instruments and analytical conditions}

All electrochemical measurements were carried out at room temperature $\left(25 \pm 1{ }^{\circ} \mathrm{C}\right.$ ) with a digital $\mathrm{pH}$ meter (WTW model PH720, Germany) utilizing an MPA-ondansetron PVC matrix membrane sensor with calomel reference electrodes (Gallenkamp, USA). A reference electrode of glass/Ag AgCl was constructed for $\mathrm{pH}$ estimates. The ion-selective electrode contained an inner solution of $0.01 \mathrm{M}$ of ondansetron solution.

\subsection{Preparation of the PVC sensor membrane}

The ion pair system was formed by $100 \mathrm{~mL}$ of $1.0 \times 10^{-1} \mathrm{M} \mathrm{ODH}$ solution and $100 \mathrm{~mL}$ of $1.0 \times 10^{-1} \mathrm{M}$ aqueous MPA. The resulting precipitate was filtered and washed with distilled water, and then left to dry. The film (membrane) was prepared by dissolving $0.170 \mathrm{mg}$ of powdered PVC, $0.40 \mathrm{mg}$ of plasticizer, and $0.040 \mathrm{mg}$ of the ion pair in $7 \mathrm{~mL}$ THF. The solvent was added to a Petri dish ( $7 \mathrm{~cm}$ in diameter), and then covered with filter paper and allowed to gradually evaporate at room temperature. A punched-out circular piece of film (membrane) was connected to a polyethylene tube with a diameter of approximately $8 \mathrm{~mm}$ in an electrode construction. ${ }^{20,21}$ A $1.0 \times$ $10^{-2} \mathrm{M}$ ODH solution was used as the interior solution in the $\mathrm{Ag} / \mathrm{AgCl}$ reference electrode. The constructed electrode was formulated and soaked for $24 \mathrm{~h}$ in $1.0 \times 10^{-2} \mathrm{M}$ ODH solution, with subsequent storage in a similar solution. The electrochemical cell for the ion-selective electrode (ISE) system used in this study is shown in Fig. 2.

\subsection{Calibration of the sensors}

The standardization of the sensors was tested by immersing the sensor into $50 \mathrm{~mL}$-beakers containing $1.0 \times 10^{-6}$ to $1.0 \times$ $10^{-2} \mathrm{M}$ ondansetron solutions. The potential was verified by plotting as a function of the logarithm of the concentration of ondansetron. The associated calibration curve was subsequently used to determine unknown ondansetron concentrations.

\subsection{Determination of the selectivity coefficient}

The selectivity coefficient $\left(K_{\mathrm{A}, \mathrm{B}}^{\mathrm{pot}}\right)$ was determined for the different electrodes by applying the matched potential method (MPM). In the MPM method, different interfering ions are added to a reference solution until the same electrode potential is recorded as that with a particular activity of elementary ions in a separate experiment. The $K_{\mathrm{MPM}}$ assumption was measured to calculate the selectivity coefficient for each interference ion from the ratio of the primary ion to interfering ion activity, as indicated in eqn (1) below:

$$
K_{\mathrm{MPM}}=\Delta a_{2} \mathrm{~A} / a_{1} B
$$

where the activity of primary solution $a_{2}$ and $a_{1}$ is the activity of the reference solution, and $a B$ denotes the interfering concentration that causes the same $\Delta E^{{ }^{19}}$

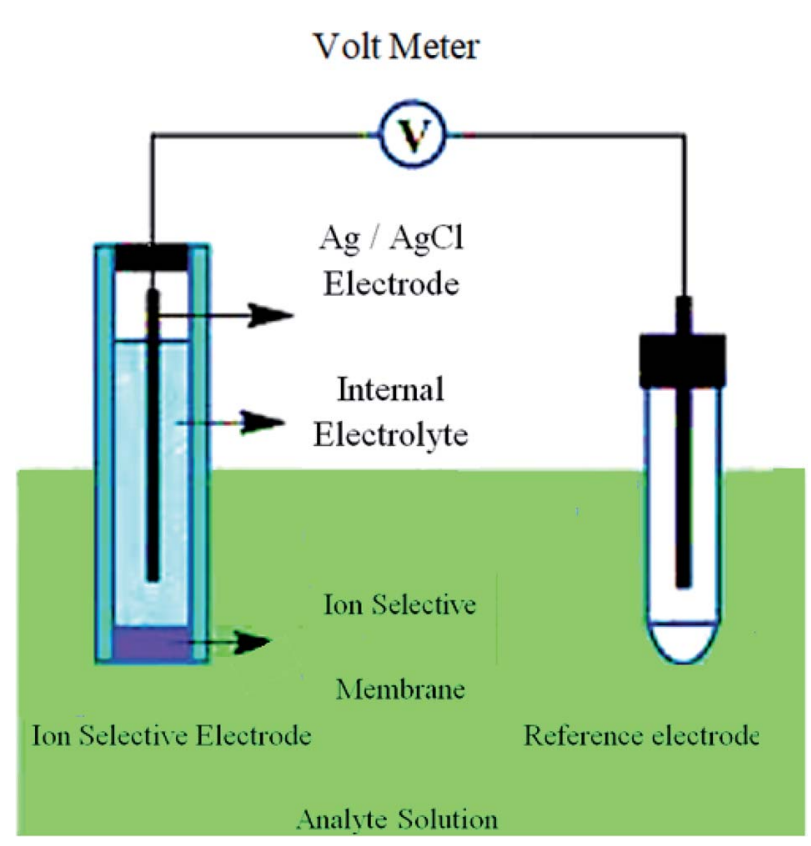

Fig. 2 Ion-selective electrodes in an electro-analytical cell. 


\section{Results and discussion}

\subsection{Characterization of the sensor}

We devised a specific method of preparing plasticized PVC matrix membrane sensors using MPA-ODH with suitable ionophores. Four types of ion-selective plasticizer membranes were formed to increase the diffusional mobility of the analysts and electroactive complex. A detailed standard protocol was investigated for applying the electrochemical technique to assess the ondansetron sensors. The response to the Nernst equation with respect to the potential-defining spaces in the solution was also considered. In this study, the sensor was activated before use by soaking in ondansetron solution for approximately two days. A series of $7.3 \times 10^{-5}$ to $1.0 \times 10^{-2}, 6.6 \times 10^{-6}$ to $1.0 \times 10^{-2}, 1.0$ $\times 10^{-5}$ to $1.0 \times 10^{-2}$, and $2.0 \times 10^{-5}$ to $1.0 \times 10^{-2} \mathrm{M}$ solutions for DBPH-, O-NPOE-, DOPH-, and DBP-ondansetron anodes was prepared to study the response of the electrode as a function of nominal Nernstian behavior that remained similar to the standard conditions. ${ }^{19}$

The data in Table 1 show an accurate response and high reproducibility for the $O-\mathrm{NPOE}, \mathrm{DBPH}, \mathrm{DOPH}$, and DBP films. The slope of the graph was $59.61 \pm 0.50$ for $\mathrm{DBPH}$, while the other slopes slightly decreased to $57.71 \pm 0.23,53.01 \pm 0.14$, and $53.20 \pm 0.35 \mathrm{mV}$ per decade for DBPH, DOPH, and DBP, respectively. It is clear that the four types provide a linear response with a satisfactory lifetime. These sensors could, however, provide an analytical signal for measuring ondansetron hydrochloride.

\subsection{Effect of time}

Time response is an important factor for use in ion-selective electrodes, and it is usually dependent on the time required for the system to reach equilibrium. An interesting observation was the stability of the potential, and chemical equilibrium in $10^{-3} \mathrm{M}$ ondansetron solution resulted in $30,32,31$, and 29 seconds for sensors $O$-NPOE, DBPH, DOPH, and DBP, respectively. The response of the electrode can disrupt the nonlinearity, and this error could decrease the efficiency of the electrode. In this case, the potential at equilibrium was less stable, and the sensor could display uncertainty in the linear response to the Nernst equation. In some cases, it was found that uncertainty was recorded for potentiometric titration of the order of potential measurements, and these differences were approximately $\pm 5 \mathrm{mV}$ e.m.f. ${ }^{20}$ In a study for measuring

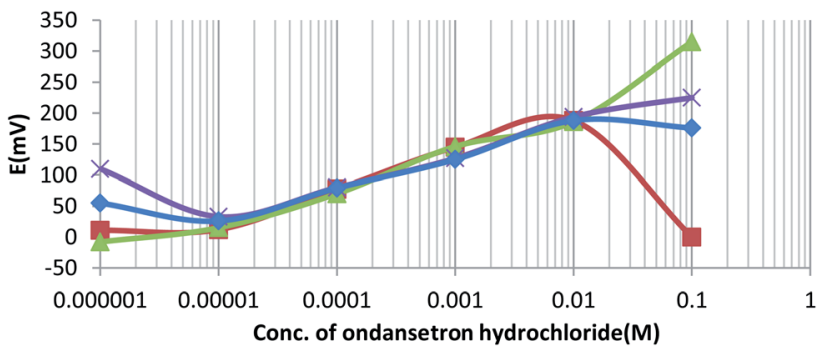

Fig. 3 Potentiometric response of ondansetron PVC matrix membrane sensors.

metoclopramide hydrochloride by PVC using a similar apparatus, the authors noted that the PVC membrane produced linear responses to the Nernst equation, while the day-to-day reproducibility of the sensor showed a decrease in the potential measurements of approximately $\pm 0.5 \mathrm{mV}$ for the same solutions. ${ }^{20}$

The data in Fig. 3 show that the change in the potential for the four electrodes in different concentrations of ondansetron solutions is in satisfactory agreement with the Nernst equation. However, the four electrodes gave slight deviations in analytical signals above $0.01 \mathrm{M}$. Previously, it has been shown that accurate measurements above $0.01 \mathrm{M}$ could be clearly obtained when the reaction mixture was heated to $60{ }^{\circ} \mathrm{C}$. This was due to reaching the optimum reaction time for the charge-transfer complexation to occur between ondansetron base as an nelectron donor with chloranil as a $\pi$-acceptor to produce a colored complex. ${ }^{21}$ However, the quantitation of ODH in all four prepared electrodes at a concentration range lower than $10^{-5} \mathrm{M}$ could not be feasible without a fitting of accumulation of transport ions, which would minimize the ion exchange of the ion-pair with competing endogenous ions. ${ }^{22}$

All prepared sensors were in good agreement with the life expectancy values of $41,36,18$, and 20 days for the $O$-NPOE-, DBPH-, DOPH-, and DBP-based membrane sensors, respectively. Therefore, in most cases, it is assumed that the differences between the responses of the four membranes are dependent on the filtering of the ion pair from the membranes. ${ }^{6}$

Fig. $4 \mathrm{a}$ and $\mathrm{b}$ shows the characterization of ondansetron with ion pair and pure drug formulation. The graph is split into two parts, and they indicate wavelength measurements of the ion pair productions. The data are similar to those expected from the previous study showing the functional groups for

Table 1 The value of parameters for ondansetron hydrochloride-selective electrodes

\begin{tabular}{|c|c|c|c|c|}
\hline Parameters & Electrode 1 DBPH & Electrode 2 NPOE & Electrode 3 DOPH & Electrode 4 DBP \\
\hline Slope (mV per decade) & $59.61 \pm 0.50$ and & $57.71 \pm 0.23$ & $53.01 \pm 0.14$ & $53.20 \pm 0.35$ \\
\hline Limit of detection (M) & $3.00 \times 10^{-6}$ & $2.53 \times 10^{-6}$ & $4.50 \times 10^{-6}$ & $8.10 \times 10^{-6}$ \\
\hline Correlation coefficient & 0.9911 & 0.9985 & 0.9915 & 0.9962 \\
\hline Linear range $\left(\mathrm{mol} \mathrm{L}^{-1}\right)$ & $7.3 \times 10^{-5}$ to $1.0 \times 10^{-2}$ & $6.6 \times 10^{-6}$ to $1.0 \times 10^{-2}$ & $1.0 \times 10^{-5}$ to $1.0 \times 10^{-2}$ & $2.0 \times 10^{-5}$ to $1.0 \times 10^{-2}$ \\
\hline $\mathrm{pH}$ range & $2.5-5.5$ & $3.5-5.0$ & $4.0-5.5$ & $4.0-5.5$ \\
\hline Time (s) & 30 & 32 & 31 & 29 \\
\hline Regression equation, $Y=m X+b$ & $Y=25.884 \ln (x)+314.1$ & $Y=25.0594 \ln (x)+303.2$ & $Y=23.018 \ln (x)+294$ & $Y=23.1044 \ln (x)+290.7$ \\
\hline Lifetime (day) & 41 & 36 & ( & 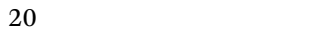 \\
\hline
\end{tabular}




\section{(a) Ion pair ODH-MPA}

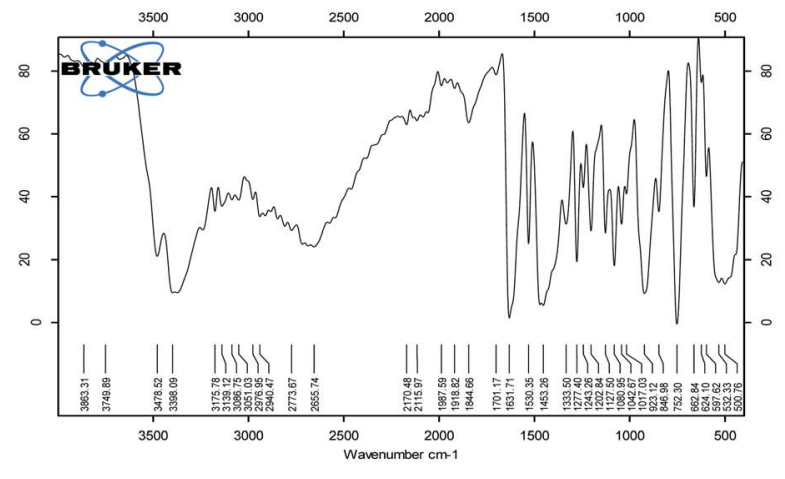

Sample Name: Sample description

\section{(b). Pure drug ODH}

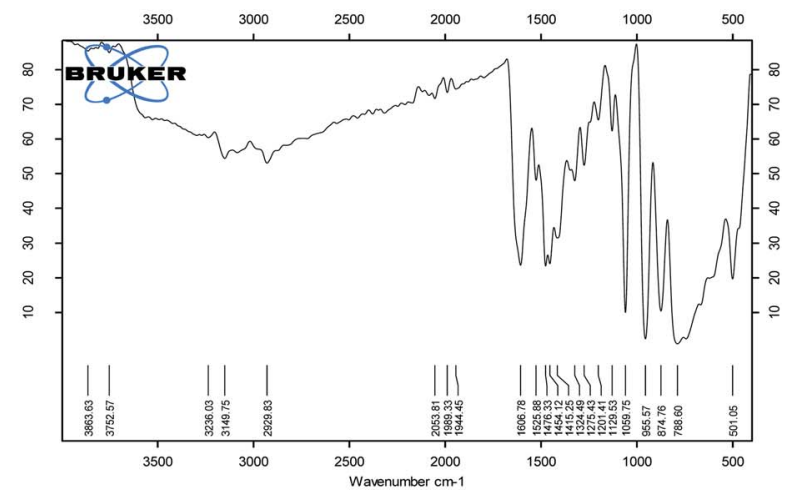

Sample Name: Sample description

Fig. 4 FTIR spectrum of (a) ion pair ODH-MPA and (b) pure drug ODH.

ondansetron with an ion pair. The Fourier transform infrared (FTIR) spectroscopy results for ondansetron show intense bands at $3483.41 \mathrm{~cm}^{-1}, 2910.11 \mathrm{~cm}^{-1}$, and $1638.7 \mathrm{~cm}^{-1}$, which correspond to the presence of the $\mathrm{NH}$ group, $\mathrm{C}-\mathrm{C}$-aromatic group, and C-C-aliphatic group, respectively. ${ }^{23}$

\subsection{Effect of pH}

The performances of the membranes in electrodes mostly depend on the potentiometric responses. One of the important factors is the presence of hydrogen ion. To further understand the potentiometric responses of the O-NPOE-, $\mathrm{DBPH}-$-, DOPH-, and DBP-based membrane sensors, they were tested with the standard addition of $10^{-3} \mathrm{M}$ ondansetron solution in a $\mathrm{pH}$ range of 1.2-12.4, as shown in Table 2. An adjustment of $\mathrm{pH}$ was achieved using diluted solutions of either sodium hydroxide or hydrochloric acid. Fig. 5 shows that the $\mathrm{pH}$ of 2.5-5.5 for DBPH, 3.5-5.5 for NPOE, and 4.0-5.5 for DOPH and DBP did not

Table $2 \mathrm{pH}$ range for ondansetron hydrochloride electrodes

\begin{tabular}{lll}
\hline Electrode no. & Composition & Range of $\mathrm{pH}$ \\
\hline 1 & ODH-MPA-DBPH & $2.5-5.5$ \\
2 & ODH-MPA-NPOE & $3.5-5.0$ \\
3 & ODH-MPA-DOPH & $4.0-5.5$ \\
4 & ODH-MPA-DBP & $4.0-5.5$
\end{tabular}

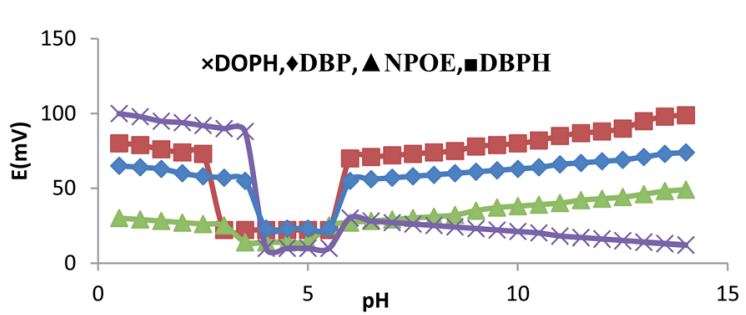

Fig. $5 \mathrm{pH}$ range for $\mathrm{ODH}$ electrodes in $10^{-3} \mathrm{M}$ ondansetron hydrochloride solution. significantly affect the sensor response. A much slower response of the membrane was obtained at $\mathrm{pH}<2.00$. This could be attributed to competitive binding of hydrogen ion at the surface of the membrane, while at $\mathrm{pH}>6$, the electrode function remained unaltered with a slight change in $\mathrm{pH}$ due to progressive precipitation of high alkali solution. ${ }^{24}$

\subsection{Effect of interfering ions}

Having shown that the presence of ion pairs in the membrane increases the selectivity of the electrode and enables quantification of the ondansetron solutions, the next step was to examine the influences in different inorganic anions. The selectivity coefficients $\left(k_{\text {potodH }}, B\right)$ are representative of the activity ratio of primary and interfering ions. They are also an essential parameter that refers to the operability of the electrodes, as it is generally known that high selectivity values refer to the high free ions that confer a smaller effect than the other interfering ions in the solution. Table 3 shows that the results are logical given the acceptable selectivity for ondansetron solutions in the presence of numerous inorganic anions. ${ }^{25,26}$

\subsection{Measuring the pharmaceutical form of ondansetron}

Tests were performed to ensure that the electrodes were valid for measuring ondansetron. All electrodes underwent the direct, standard (SAM), and multi-standard potentiometric method (SAMS) to determine the concentration of $10^{-4} \mathrm{M}$ and $10^{-3} \mathrm{M}$ ondansetron solutions for all electrodes. These data are shown in Table 6, and in all cases, it was assumed that there was considerably high precision and linearity with a low detection limit for all values obtained using the potentiometric titration method for all plasticizer-based membranes, and they emphasize the improved performances of the electrodes, as summarized in Tables 4-7. The performances of the prepared membrane electrodes were similar to those previously mentioned in the literature. In the same context, a study by Nigović examined the electrochemical behavior of ondansetron on the multi-walled carbon nanotubes of a Nafion polymer composite in a glassy carbon electrode. ${ }^{27}$ The quantification of 
Table 3 Selectivity coefficient value for different interfering ions using (ODH-MPA) electrodes

$K_{\mathrm{A}, \mathrm{B}}$ calculation for $10^{-3} \mathrm{M}$ ODH solution

\begin{tabular}{|c|c|c|c|c|}
\hline Ion interference & Electrode 1 & Electrode 2 & Electrode 3 & Electrode 4 \\
\hline $\mathrm{Li}^{1+}$ & $2.0954 \times 10^{-2}$ & $4.9168 \times 10^{-2}$ & $9.1845 \times 10^{-2}$ & $6.0186 \times 10^{-2}$ \\
\hline $\mathrm{Na}^{1+}$ & $6.9934 \times 10^{-2}$ & $5.6210 \times 10^{-2}$ & $7.9220 \times 10^{-2}$ & $5.3314 \times 10^{-2}$ \\
\hline $\mathrm{K}^{1+}$ & $3.3789 \times 10^{-2}$ & $1.1897 \times 10^{-2}$ & $6.6543 \times 10^{-2}$ & $8.0267 \times 10^{-2}$ \\
\hline $\mathrm{Ca}^{2+}$ & $8.5077 \times 10^{-3}$ & $8.4398 \times 10^{-3}$ & $8.0300 \times 10^{-3}$ & $1.1125 \times 10^{-3}$ \\
\hline $\mathrm{Mg}^{2+}$ & $5.8124 \times 10^{-3}$ & $5.9855 \times 10^{-3}$ & $2.2346 \times 10^{-3}$ & $3.4676 \times 10^{-3}$ \\
\hline $\mathrm{Zn}^{2+}$ & $1.6589 \times 10^{-3}$ & $4.5783 \times 10^{-3}$ & $7.7865 \times 10^{-3}$ & $3.5654 \times 10^{-3}$ \\
\hline $\mathrm{Cr}^{3+}$ & $4.4532 \times 10^{-4}$ & $6.8754 \times 10^{-4}$ & $7.7589 \times 10^{-4}$ & $3.5435 \times 10^{-4}$ \\
\hline $\mathrm{Fe}^{3+}$ & $5.6330 \times 10^{-4}$ & $7.6540 \times 10^{-4}$ & $5.1034 \times 10^{-4}$ & $2.0147 \times 10^{-4}$ \\
\hline $\mathrm{Al}^{3+}$ & $9.1044 \times 10^{-4}$ & $6.0366 \times 10^{-4}$ & $6.9305 \times 10^{-4}$ & $8.0509 \times 10^{-4}$ \\
\hline
\end{tabular}

Table 4 Potentiometric methods for ODH-MPA-DBPH electrodes in $10^{-3}$ and $10^{-4} \mathrm{M}$ ondansetron solutions

\begin{tabular}{|c|c|c|c|c|}
\hline \multirow[b]{2}{*}{ Sample } & \multicolumn{4}{|c|}{$\begin{array}{l}\text { Potentiometric methods for ODH-MPA-DBPH electrodes in } 10^{-3} \text { and } 10^{-4} \mathrm{M} \\
\text { ondansetron solutions }\end{array}$} \\
\hline & Direct & SAM & SAMS & Titration \\
\hline $1 \times 10^{-3}(\mathrm{M})$ & $0.9596 \times 10^{-3}$ & $0.9762 \times 10^{-3}$ & $0.9817 \times 10^{-3}$ & $0.9833 \times 10^{-3}$ \\
\hline Relative standard deviation (RSD) $)^{a}(\%)$ & 1.28 & 1.59 & - & - \\
\hline Recovery (rec) (\%) & 95.96 & 97.62 & 98.17 & 98.33 \\
\hline Relative error (RE) (\%) & -4.04 & -2.38 & -1.90 & -1.67 \\
\hline $1 \times 10^{-4} \mathrm{M}$ & $0.9650 \times 10^{-4}$ & $0.9790 \times 10^{-4}$ & $0.9798 \times 10^{-4}$ & $0.9848 \times 10^{-4}$ \\
\hline $\operatorname{RSD}^{a}(\%)$ & 3.12 & 0.46 & - & - \\
\hline Recovery (\%) & 96.50 & 97.90 & 97.98 & 98.48 \\
\hline Relative error (\%) & -3.12 & -2.10 & -2.02 & -1.52 \\
\hline
\end{tabular}

ondansetron concentrations in coated tablets was reported as electrochemical data.

Recovery studies of drugs in serum samples were performed using the standard addition method, with $98.77 \%$ recovery of ondansetron as protonated drug molecules on a Nafion surface matrix. ${ }^{27}$ Another comparable study by Ninama $e t$ al. measured ODH concentration using the solid-phase extraction chromatography-mass spectrometry method. ${ }^{16}$ The work reported that the percent accuracy of samples prepared with different biological matrixes was found to be $91.88 \%$, and wet extract stability was found to be $43 \mathrm{~h} 30 \mathrm{~min}$ at $5 \pm 3{ }^{\circ} \mathrm{C} .{ }^{16}$
For the current method, the recovery measurements for prepared electrodes were approximately $97.90 \%$ using the standard addition method. The precision and accuracy of the method expressed as recovery\% was found to be approximately $2.1 \% .^{9}$ The results obtained were within the acceptable range and were higher than those observed in the biological matrix. ${ }^{16}$ The values are also in accordance with the effective accuracy measurements of ODH solutions, as shown in Table 4.

Additional tests were performed after the application of the improved electrodes in pure solutions of ondansetron. The plasticized PVC matrix membranes were used to measure

Table 5 Potentiometric methods for ODH-MPA-NPOE electrodes in $10^{-3}$ and $10^{-4} \mathrm{M}$ ondansetron solutions

\begin{tabular}{|c|c|c|c|c|}
\hline \multirow[b]{2}{*}{ Sample } & \multicolumn{4}{|c|}{ Potentiometric methods for ODH-MPA-NPOE electrodes in $10^{-3}$ and $10^{-4} \mathrm{M}$ ondansetron solutions } \\
\hline & Direct & SAM & SAMS & Titration \\
\hline $1 \times 10^{-3}$ & $0.9533 \times 10^{-3}$ & $0.9870 \times 10^{-3}$ & $0.9814 \times 10^{-3}$ & $0.9839 \times 10^{-3}$ \\
\hline RSD (\%) & 1.64 & 1.06 & - & - \\
\hline $\operatorname{Rec}(\%)$ & 95.33 & 98.70 & 98.14 & 98.39 \\
\hline $\mathrm{RE}(\%)$ & -4.67 & -1.30 & -1.86 & -1.61 \\
\hline $1 \times 10^{-4}$ & $0.9482 \times 10^{-4}$ & $0.9817 \times 10^{-4}$ & $0.9860 \times 10^{-4}$ & $0.9877 \times 10^{-4}$ \\
\hline RSD (\%) & 4.92 & 1.36 & - & - \\
\hline $\operatorname{Rec}(\%)$ & 94.82 & 98.17 & 98.60 & 98.77 \\
\hline RE (\%) & -5.18 & -1.83 & -1.40 & -1.23 \\
\hline
\end{tabular}


Table 6 Potentiometric methods for ODH-MPA-DOPH electrodes in $10^{-3}$ and $10^{-4} \mathrm{M}$ of ondansetron solutions

\begin{tabular}{|c|c|c|c|c|}
\hline \multirow[b]{2}{*}{ Sample } & \multicolumn{4}{|c|}{ Potentiometric methods for ODH-MPA-DOPH electrodes in $10^{-3}$ and $10^{-4} \mathrm{M}$ ondansetron solutions } \\
\hline & Direct & SAM & SAMS & Titration \\
\hline $1 \times 10^{-3}$ & $0.9538 \times 10^{-3}$ & $0.9767 \times 10^{-3}$ & $0.9733 \times 10^{-3}$ & $0.98100 \times 10^{-3}$ \\
\hline RSD (\%) & 3.72 & 1.62 & - & - \\
\hline $\operatorname{Rec}(\%)$ & 95.38 & 97.67 & 97.33 & 98.10 \\
\hline $\mathrm{RE}(\%)$ & -4.62 & -1.62 & -2.67 & -1.90 \\
\hline $1 \times 10^{-4}$ & $0.9582 \times 10^{-4}$ & $0.9841 \times 10^{-4}$ & $0.9630 \times 10^{-4}$ & $0.9857 \times 10^{-4}$ \\
\hline RSD (\%) & 3.24 & 1.04 & - & - \\
\hline $\operatorname{Rec}(\%)$ & 95.82 & 98.41 & 96.30 & 98.57 \\
\hline $\mathrm{RE}(\%)$ & -4.18 & -1.59 & -3.70 & -1.34 \\
\hline
\end{tabular}

Table 7 Results for potentiometric methods for ODH-MPA-DOP electrodes in $10^{-3}$ and $10^{-4} \mathrm{M}$ ondansetron solutions

\begin{tabular}{|c|c|c|c|c|}
\hline \multirow[b]{2}{*}{ Sample } & \multicolumn{4}{|c|}{ Potentiometric methods for ODH-MPA-DOP electrodes in $10^{-3}$ and $10^{-4} \mathrm{M}$ ondansetron solutions } \\
\hline & Direct & SAM & SAMS & Titration \\
\hline RSD (\%) & 3.13 & 1.07 & - & - \\
\hline $\operatorname{Rec}(\%)$ & 96.87 & 98.18 & 97.04 & 98.23 \\
\hline RE (\%) & -3.13 & -1.82 & -2.96 & -1.77 \\
\hline $\operatorname{Rec}(\%)$ & 97.21 & 96.80 & 98.52 & 98.55 \\
\hline $\mathrm{RE}(\%)$ & -2.14 & -3.2 & -1.48 & -1.45 \\
\hline
\end{tabular}

Table 8 Application of ODH electrodes to measure ondansetron dosage

Direct potentiometric methods at $1.00 \times 10^{-3} \mathrm{M} \mathrm{ODH}$

Zofran tablet - ondansetron hydrochloride, $8 \mathrm{mg}$

Concentration of ODH (M)

$\operatorname{Rec}(\%)$

RE (\%)

Zofran tablet - ondansetron hydrochloride, $4 \mathrm{mg}$ Concentration of ODH (M)

$\operatorname{Rec}(\%)$

$\mathrm{RE}(\%)$

Zofran tablet - ondansetron hydrochloride, $4 \mathrm{mg}$ $\operatorname{Rec}(\%)$

RE (\%)

Electrode 1
$0.9761 \times 10^{-3}$
97.61
-2.39

Electrode 1 $9.8007 \times 10^{-3}$ 98.00

$-2.00$

Reference method ${ }^{21}$

99.42

0.61

\section{Electrode 2 \\ $9.7443 \times 10^{-3}$ \\ 97.44 \\ $-2.56$}

Electrode 2

$9.6739 \times 10^{-3}$

96.73

$-3.27$

Electrode 3
$9.6535 \times 10^{-3}$
96.53
-3.47

Electrode 3

$9.7123 \times 10^{-3}$

97.12

$-2.88$
Electrode 4

$9.5815 \times 10^{-3}$

95.81

$-4.19$

Electrode 4

$9.6908 \times 10^{-3}$ 96.90

$-3.10$ pharmaceutical preparations, and the data are shown in Table 8. It was noted that all electrodes were able to adequately measure the concentration of ondansetron, and these data indicate that the proposed potentiometric method is applicable for quality control of medicinal preparations. ${ }^{28}$

\section{Conclusion}

This work has demonstrated the importance of PVC sensors in potentiometric applications for measurement of ondansetron in two pharmaceutical formulations. The ODH-MPA-DBPH membrane sensor was more optimal than the other prepared electrodes with respect to Nernstian response, reproducibility, and sensitivity. The results of this investigation enable the direct prediction of ondansetron. Our data indicate that polymeric membrane sensors are unique for characterizations at wide ranges of $\mathrm{pH}$ (from 2.5 to 5.5). Our methodology was also found to be an important design process because a selective response toward ondansetron in the presence of all the expected interfering ions was exhibited.

\section{Conflicts of interest}

There are no conflicts to declare. 


\section{References}

1 R. Asad, I. A. Subhan, K. Aslam and A. Rehman, Application of certain $\pi$-acceptors for the spectrophotometric determination of ondansetron in pharmaceutical formulations, Anal. Chem., 2007, 6(2), 43-47.

2 British pharmacopoeia, Version 17, Copyright by, London, 2012.

3 British Pharmacopoeia, Her Majesty, Stationery Office, London, 2003, 2.

4 S. Mujbaile, P. Prasad and S. Wate, Simultaneous estimation of Ondansetron and Pantoprazole in solid dosage form by first derivative spectroscopy method, Tablet 4, no. 40, 2012, 100-117.

5 M. Zaabal, M. Doulache, N. K. Bakirhan, S. Kaddour, B. Saidat and S. A. Ozkan, A facile strategy for construction of sensor for detection of ondansetron and investigation of its redox behavior and thermodynamic parameters, Electroanalysis, 2019, 31(7), 1279-1290.

6 S. Jadhav, R. Kharat, A. Ansari and A. Tamboli, Estimation of Ondansetron Hydrochloride in bulk and formulation by second order derivative area under curve UVSpectrophotometric Methods, PharmaTutor, 2015, 3(8), 4246.

7 S. N. Gayatri, V. M. N. Biju and A. M. Starvin, Determination of Ondansetron by Spectrofluorimetry: Application to Forced Degradation Study, Pharmaceuticals and Human Plasma, J. Fluoresc., 2019, 29(1), 203-209.

8 R. Kalaichelvi, B. Madhava Rao, S. Manikanta, G. Gopinath, M. Usha, D. Venkata Ramana, D. Srinivasa Rao and E. Jayachandran, UV spectrophotometric method for determination of ondansetron hydrochloride in pure and its formulation, Int. J. Pharm. Pharm. Sci., 2012, 4(4), 151152.

9 P. V. Colthup, C. C. Felgate, J. L. Palmer and N. L. Scully, Determination of ondansetron in plasma and its pharmacokinetics in the young and elderly, J. Pharm. Sci., 1991, 80(9), 868-871.

10 A. M. I. Mohamed and N. A.-L. Mohamed, Development and validation of RP-HPLC method for simultaneous determination of ondansetron hydrochloride and granisetron hydrochloride in their admixtures with pantoprazole sodium, Thai J. Pharm. Sci., 2020, 44(2), 82-90.

11 A. Anilkumar, Formulation of Ondansetron HCl Matrix Tablets with Microenvironmental $\mathrm{pH}$ Modifier for Improved Dissolution and Bioavailability under Hypochlorhydria, Asian J. Pharm., 2016, 10(3), 188-197.

12 Z. Dedania, R. Dedania, V. Karkhanis, G. Vidya Sagar, M. Baldania and N. R. Sheth, RP-HPLC method for simultaneous estimation of omeprazole and ondansetron in combined dosage forms, Asian J. Res. Chem., 2009, 2(2), 108-111.

13 F. C. Chen, L.-H. Wang, J. Guo, X.-Y. Shi and B.-X. Fang, Simultaneous determination of dexamethasone, ondansetron, granisetron, tropisetron, and azasetron in infusion samples by HPLC with DAD detection, J. Anal. Methods Chem., 2017, 2017, 1-6.

14 F. Faridbod, F. Mizani, M. R. Ganjali and P. Norouzi, Determination of ondansetron hydrochloride by a liquid membrane potentiometric sensor based on room temperature ionic liquids, Int. J. Electrochem. Sci., 2013, 8(8), 10461-10472.

15 S. S. M. Hassan, W. H. Mahmoud, M. A. F. Elmosallamy and M. H. Almarzooyi, Determination of diclofenac in pharmaceutical preparations using a novel PVC membrane sensor, Int. J. Pharm. Sci., 2003, 58(no. 1), 29-31.

16 G. Ninama, R. Patel, M. Patel and G. Shah, Solid phase extraction liquid chromatography mass spectrometry method with electrospray ionization for the determination of Ondansetron in human plasma: Development and validation consideration, Arabian J. Chem., 2017, 10, S3135-S3141.

17 F. Faridbod, F. Mizani, M. R. Ganjali and P. Norouzi, Determination of ondansetron hydrochloride by a liquid membrane potentiometric sensor based on room temperature ionic liquids, Int. J. Electrochem. Sci., 2013, 8(8), 10461-10472.

18 A. P. Abbott, S. S. M. Alabdullah, A. Y. M. Al-Murshedi and K. S. Ryder, Brønsted acidity in deep eutectic solvents and ionic liquids, Faraday Discuss., 2017, 206, 365-377.

19 A. Craggs, G. J. Moody and J. D. R. Thomas, PVC matrix membrane ion-selective electrodes. Construction and laboratory experiments, J. Chem. Educ., 1974, 51(8), 541.

20 G. A. E. Mostafa, PVC matrix membrane sensor for potentiometric determination of metoclopramide hydrochloride in some pharmaceutical formulations, $J$. Pharm. Biomed. Anal., 2003, 31(3), 515-521.

21 A. Raza, A. S. Ijaz and U. Rasheed, Spectrophotometric determination of ondansetron hydrochloride in pharmaceutical bulk and dosage forms, J. Chin. Chem. Soc., 2007, 54(1), 223-227.

22 J. M. Miller, A. Dahan, D. Gupta, S. Varghese and G. L. Amidon, "Quasi-equilibrium analysis of the ion-pair mediated membrane transport of low-permeability drugs, J. Controlled Release, 2009, 137(1), 31-37.

23 S. Mulagada and S. Rao Baratam, Design and evaluation of ondansetron fast disintegrating tablets using natural polymers and modified starches as super disintegrants for the enhancement of dissolution, J. Young Pharm., 2017, $9(4), 519$.

24 M. A. F. Elmosalamy, G. J. Moody, J. D. R. Thomas and S. M. H. Saad, Poly(Vinyl Chloride) Matrix Membrane Electrodes Responsive to Thiocyanate, Perchlorate and Periodate, Anal. Lett., 1987, 20(10), 1541-1555.

25 R. Jain and R. Sharma, Cathodic adsorptive stripping voltammetry of an anti-emetic agent Granisetron in pharmaceutical formulation and biological matrix, $J$. Pharm. Anal., 2012, 2(6), 443-449.

26 A. M. Abass, Preparation and Application of Tetracycline Hydrochloride Liquid membrane Electrodes, Al-Nahrain Journal of Science, 2018, 21(2), 73-80. 
27 B. Nigović, M. Sadiković and M. Sertić, Multi-walled carbon nanotubes/Nafion composite film modified electrode as a sensor for simultaneous determination of ondansetron and morphine, Talanta, 2014, 122, 187-194.
28 H. A. Mohammed and A. M. Abass, Poly(vinyl chloride) matrix membrane sensors for the quantification of cyclizine hydrochloride in pure and pharmaceutical preparations, in AIP Conference Proceedings, AIP Publishing LLC, 2020, vol. 2213, no. 1, p. 020034. 